\title{
Hydroxylamine as an oxygen nucleophile. Structure and reactivity of ammonia oxide
}

\author{
A. J. Kirby,* J. E. Davies, T. A. S. Brandão, P. F.da Silva, W. R. Rocha, F. Nome*
}

Electronic Supporting Information

\section{Details of the crystallography.}

\section{Calculations. Tables S1 - S4.}

Calculated geometries and energies for hydroxylamine, ammonia oxide and hydroxylamine hydrochloride, in the gas phase and with solvation by water molecules.

\section{Details of the crystallography.}

The crystals were first obtained from the decomposition of 2-chloroacetohydroxamic acid in solution in alcohol at $\mathrm{pH}$ 6. They are best prepared by mixing equal volumes of $1 \mathrm{M}$ $\mathrm{NH}_{2} \mathrm{OH} . \mathrm{HCl}$ and $0.5 \mathrm{M} \mathrm{KOH}$ in hot methanol, giving a solution containing equal quantities of $\mathrm{NH}_{2} \mathrm{OH}$ and its hydrochloride. After filtering off the $\mathrm{KCl}$ which immediately precipitates, slow evaporation of the solvent at room temperature gives colorless crystals, mp $86-87^{\circ} \mathrm{C}$. These show two well-resolved ${ }^{15} \mathrm{~N}$ (natural abundance) signals, at -312.7 and $-314.6 \mathrm{ppm}$ (relative to $\mathrm{NO}_{3}^{-}$) in the solid state NMR.

Crystal data: $\mathrm{ClH}_{7} \mathrm{~N}_{2} \mathrm{O}_{2}, \mathrm{Mw}=102.53$, colourless prism $0.35 \times 0.18 \times 0.07 \mathrm{~mm}^{3}$, monoclinic $\mathrm{P} 21 / \mathrm{c} \quad$ (No. 14), $\quad \mathrm{a}=7.2167(1), \quad \mathrm{b}=8.1338(2), \quad \mathrm{c}=7.0381(2) \AA, \quad \beta=92.35(1)^{\circ}, \quad \mathrm{Z}=4$, $\mathrm{V}=412.79(2) \AA 33, \mathrm{~T}=120(2) \mathrm{K}, \mathrm{DX}=1.650 \mathrm{~g} \mathrm{~cm}-3, \lambda=0.71073 \AA, \mu=0.762 \mathrm{~mm}-1$, Nonius Kappa CCD diffractometer equipped with an Oxford Cryosystems Cryostream cooling apparatus, $3.78^{\circ}<\theta<45.27^{\circ}, 12868$ measured reflections, 3441 independent (Rint=0.025), 3071 with $\mathrm{I}>2 \sigma(\mathrm{I})$. The structure was solved by direct methods (SHELXS-97) and refined by least squares (SHELXL-97) using Chebyshev weights on Fo2 to R1 $=0.023$, wR2 $=0.056$

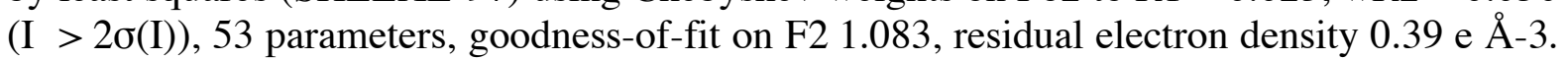
All hydrogen atoms were located unambiguously in the final difference map. For the refinement, the $-\mathrm{NH}_{3}$ groups were treated as rigid groups with idealized tetrahedral geometry and the hydrogen atoms of these groups were assigned a common isotropic displacement parameter (there are no significant differences if the structure is refined without these restraints). The coordinates of the $-\mathrm{OH}$ hydrogen atom were refined successfully without any restraints.

Further details of the crystal-structure investigation may be obtained from the Fachinformationszentrum Karlsruhe, 76344 Eggenstein-Leopoldshafen, Germany (fax (+49) 7247-808-666; e-mail crysdata@fiz-karlsruhe.de) on quoting the deposition number CSD415541. 


\section{Calculations}

Geometries of 1 and $1 \mathrm{z}$ in the gas phase and in the presence of solvating $\mathrm{H}_{2} \mathrm{O}$

Table S1. B3LYP/6-311++G(d,p) geometries for hydroxylamine and ammonia oxide in the gas phase, ${ }^{a}$ and PCM/B3LYP/6-311++G(d,p) single-point energies for the optimized structures.

\begin{tabular}{|c|c|c|}
\hline & $\mathrm{H}_{2} \mathrm{NOH}$ & $\mathrm{H}_{3} \mathrm{NO}^{\mathrm{b}}$ \\
\hline$R(\mathrm{~N}-\mathrm{O})$ & 1.444 & 1.367 \\
\hline$R(\mathrm{O}-\mathrm{H})$ & 0.963 & \\
\hline$R(\mathrm{~N}-\mathrm{H})$ & 1.018 & 1.034 \\
\hline$\theta(\mathrm{N}-\mathrm{O}-\mathrm{H})$ & 102.8 & \\
\hline$\theta(\mathrm{H}-\mathrm{N}-\mathrm{O})$ & 104.2 & 113.1 \\
\hline$\theta(\mathrm{H}-\mathrm{N}-\mathrm{H})$ & 106.2 & \\
\hline$q\left(\mathrm{H}_{\mathrm{a}}\right)$ & 0.250 & 0.281 \\
\hline$q\left(\mathrm{H}_{\mathrm{b}}\right)$ & 0.278 & \\
\hline$q(\mathrm{~N})$ & -0.496 & -0.365 \\
\hline$q(\mathrm{O})$ & -0.281 & -0.478 \\
\hline$E_{\text {elec }}^{\mathrm{b}}$ & -131.766887 & -131.728118 \\
\hline$G^{\mathrm{b}}$ & -131.749030 & -131.710051 \\
\hline$E_{\text {elec }}{ }^{\mathrm{PCM}, \mathrm{b}}$ & -131.781612 & -131.764816 \\
\hline$G_{\text {nuclear }}$ corr & -82.67 & -82.00 \\
\hline$\Delta G_{\mathrm{sol}}=E_{\text {elec }}^{\text {sol }}-E_{\text {elec }}^{\text {gas }}$ & -9.24 & -23.03 \\
\hline$\Delta E_{\text {elec }}$ & 24.3 & \\
\hline$\Delta G_{\text {nuclear }}$ & 0.67 & \\
\hline$\Delta G^{\circ}=\Delta G_{\text {nuclear }}+\Delta E_{\text {elec }}$ & 25.0 & \\
\hline$\Delta \Delta G_{\text {solv }}$ & -13.8 & \\
\hline $\begin{array}{l}\Delta G_{\text {sol }}^{\mathrm{o}}=\Delta G^{\mathrm{o}}+\Delta \Delta G_{\text {solv }} \\
\text { a Bond lengths in } \AA \text {, angles in } \\
\text { These values are comparable }\end{array}$ & 11.2 & \\
\hline
\end{tabular}


Table S2. B3LYP/6-31+G(d) geometries for hydroxylamine and ammonia oxide with six water molecules included explicitly as the first solvation shell, a and PCM/B3LYP/6-31+G(d) single-point energies for the optimized structures (shown below).

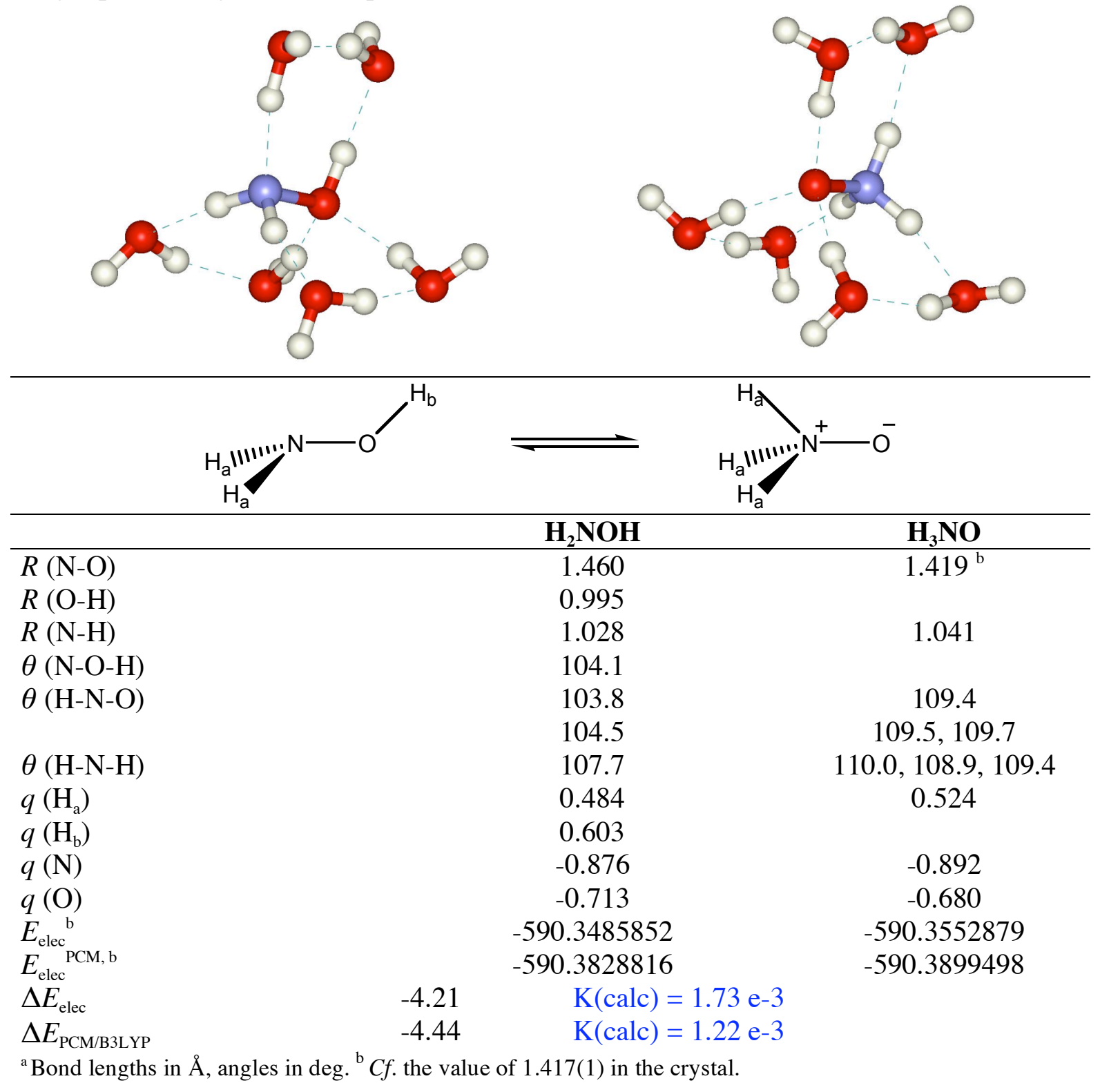


Table S3. B3LYP/6-31+G(d) geometry of hydroxylammonium in the gas phase, with four water molecules explicitly included in the first solvation-shell. ${ }^{a}$

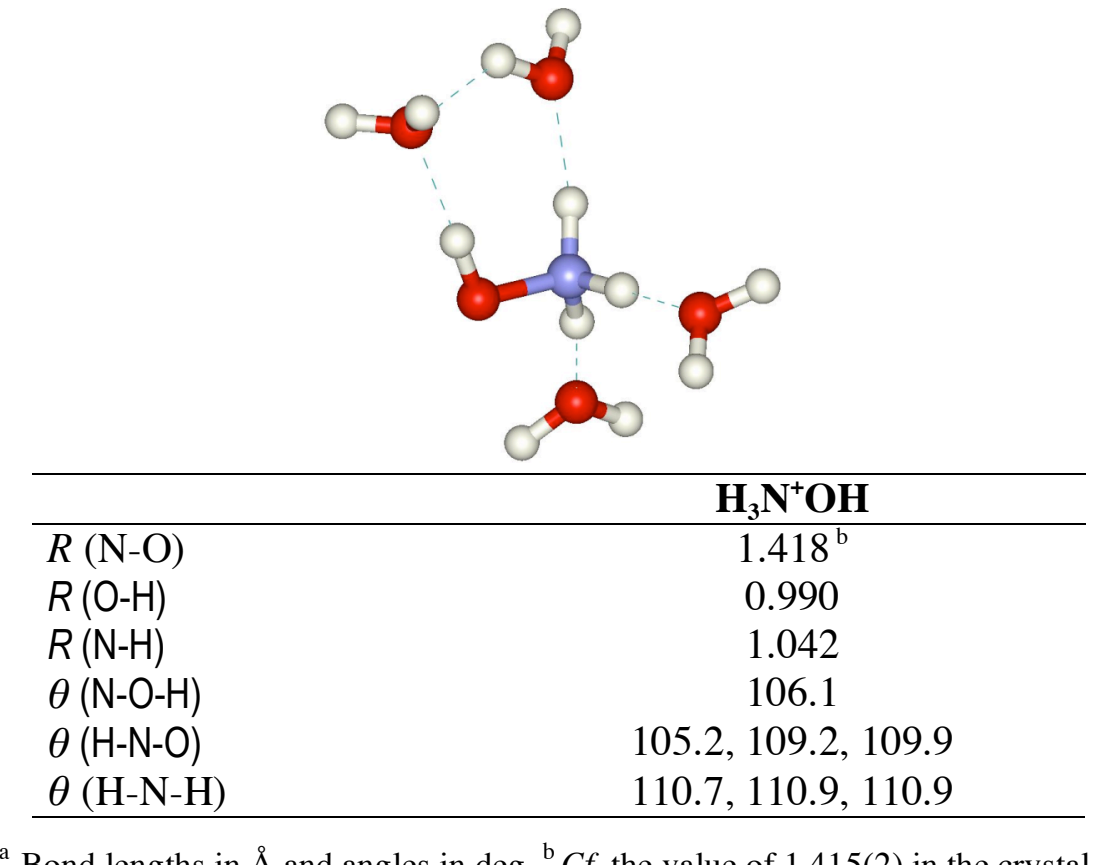

Table S4. Calculated energetics $(\mathrm{kcal} / \mathrm{mol})$ for the tautomeric process $\mathrm{NH}_{2} \mathrm{OH} \rightarrow \mathrm{NH}_{3} \mathrm{O}$ in the gas phase and in aqueous solution, at different levels of theory.

\begin{tabular}{|l|c|c|c|c|}
\hline \multicolumn{1}{|c|}{ Method } & \multicolumn{2}{|c|}{ Gas Phase } & \multicolumn{2}{c|}{ Aqueous solution } \\
\hline & $\Delta \mathbf{E}$ & $\Delta \mathbf{G}$ & $\begin{array}{c}\Delta \text { G(soln. }) \\
\text { Rigid charges }^{\mathbf{a}}\end{array}$ & $\begin{array}{c}\Delta \text { G(soln. }) \\
\text { PCM polarized }^{\mathbf{b}}\end{array}$ \\
\hline B3LYP $^{22} / 6-311++\mathrm{G}(\mathrm{d}, \mathrm{p})^{23}$ & 24.33 & 24.45 & 5.69 & -5.20 \\
\hline MP2//B3LYP/6-311++G(d,p) & 27.69 & 27.82 & 9.06 & -1.83 \\
\hline MP4(SDTQ)// B3LYP/6-311++G(d,p) & 27.47 & 27.60 & 8.84 & -2.05 \\
\hline CCSD(T) ${ }^{24} / /$ B3LYP/6-311++G(d,p) & 25.93 & 26.06 & 7.30 & -3.59 \\
\hline
\end{tabular}

${ }^{\mathrm{a}} \Delta \mathrm{G}($ soln. $)$ is the sum of $\Delta \mathrm{G}(g)$ computed at the specified level of theory and $\Delta \Delta \mathrm{G}_{\text {solv }}\left(\mathbf{N H}_{2} \mathbf{O H} \rightarrow \mathbf{N H}_{3} \mathbf{O}\right)$ calculated with the charges kept rigid on going from the gas phase to solution.

${ }^{\mathrm{b}} \Delta \mathrm{G}($ soln. $)$ is the sum of $\Delta \mathrm{G}(\mathrm{g})$ computed at the specified level of theory and $\Delta \Delta \mathrm{G}_{\text {solv }}\left(\mathbf{N H}_{\mathbf{2}} \mathbf{O H} \rightarrow \mathbf{N H}_{3} \mathbf{O}\right)$ calculated with free energy perturbation, using PCM polarized charges.

\section{References.}

(22) Becke, A. D. J. Chem. Phys. 1993, 98, 5648.

(23) (a) Ditchfield, R.; Hehre, W. J.; Pople, J. A. J. Chem. Phys. 1971, 54, 724.(b) Hehre, W. J.; Ditchfield, R.; Pople, J. Chem. Phys. 1972, 56, 2257.

(24) (a) Purvis, G. D.; Bartlett, R. J. J. Chem. Phys. 1982, 76, 1910. (b) Urban, M.; Noga, J.; Cole, S. J.;

Bartlett, R. J. J. Chem. Phys.1985, 83, 4041. 